\title{
A Slow Train or a Quick Flight? ----A Deep Reflection on Students' Choices Concerning Their Own Learning Strategies
}

\author{
Catherine Cheng Mei-seung \\ PolyU Hong Kong Community College, Hong Kong \\ cccheng@hkcc-polyu.edu.hk
}

\begin{abstract}
This paper focuses on the author's reflections as a researcher on students' choices concerning their own learning strategies, based on the findings of a pilot study in a governmentfunded ePortfolio Project (Project) in a Hong Kong Higher Education Institution (HEI). The major purpose of this pilot study is to enhance students' learning by facilitating online peer feedback in the context of an ePortfolio platform. This paper first describes the author's self-learning experience when she was a university students. The two major learning affordances of ePortfolios, which are to showcase students' artifacts and to prompt engagement and reflections between student peers, are then discussed. The next section is research methodology adopted in the pilot study. The procedure of this study is described. According to the finding, learning through exchanging feedback online in the context of ePortfolios did not gain an overwhelming support from students when compared with self-learning . While the possible reasons behind these results are discussed, recommendations for future research are also included. The last section deals with the limitations of this study and offers some concluding remarks.

Index Terms - reflections, ePortfolio, Higher Education Institution, peer feedback, self-learning
\end{abstract}

\section{Introduction}

From the author's observation, self-learning seems to be a dominant learning method for HEI students in Hong Kong. When I was still a university student, all I knew the ways to do my assignment was to stay in the library for days. We might have group project sometimes, but mostly we would divide the work into different parts and everyone focused on their own part afterwards without any sharing. Exchanging feedback with each other was not very popular at that time. This phenomenon could be best explained by Pang and Penfold [1]'s notion. They pointed out that in many Chinese societies, the whole process in the transmission of knowledge only involved students and the teacher. In this process, from students' angle, no participation from peers is needed.

However, this traditional learning method is consistently challenged by the rise of electronic learning (e-learning) Platforms, where learners have [2] "access to a curriculum made up of online and classroom components". The author has currently involved in an ePortfolio Project which aims to promote peer discussion in the context of an online ePortfolio Platform named MAHARA. The Project consists of four phases, and this study took place in Phase II (March 2012August 2012). A single case study was adopted. Based on th finding of this pilot study, this article presents the author's reflection as a researcher on students' choices concerning their own learning strategies after the implementation of this study.
To begin with, learning affordances of ePortfolio are briefly discussed, followed by the research methodology of this study. Results are analysed, followed by discussions and recommendations. Limitations of this article and conclusion are also included.

\section{LEARNing AFFordances of EPORTFOlios}

This section introduces the two major learning affordances of ePortfolios: to showcase a student's knowledge or achievement and to enhance their learning by facilitating peer feedback.

The first affordance is to showcase students' achievement. There are many functions in the ePortfolio Platform, which allow users to conduct their presentation in a way different from the paper-format. Take an online resume as an example. Students could link up their artefects, such as photos, videos, audios or websites, with their resume, so that potential employers could know more about their work in a few clicks. This is not to mention that sometimes readers feel interested not only in the finalized work, but also how the work is formed. Thus, the resume owners could share the plan, draft and/or self-reflection of their work in their ePortfolios, so as to give readers a wider picture of their learning process. In fact, it is believed that constructing and maintaining an ePortfolio could raise students' sense of ownership and the responsibility of their learning [3][4].

In addition, ePortfolio is also regarded as an excellent tool to prompt students' engagement and reflection in learning [5]. Vygotsky [6] pointed out that, learning first occurs when individuals interact with others at a social level. His "Zone of Proximal Development(ZPD)" ascertained that problem solving skill levels evolve more if youngsters could work with more experienced people. He further explained that learners did not learn in isolation from others, but from the results of social interaction with peers which could motivate and stimulate their thinking. Their cognitive thinking skills were then advanced.

\section{RESEARCH METHODOLOGY}

A qualitative case study method, which gives a holistic and an in-depth understanding [7] on students' choices concerning their own learning strategies is adopted in this study. This case study not only reflecting stories of our participants, but also providing a reference, which may help to generalize across a larger set of units [8]. 
There were total 168 participants, and they were the registered students for the courses "Introduction to Sociology Culture” (Group A), and "Digital Video Production” (Group B) in the autumn semester of 2011-12 (Table 1).

TABLE 1 The Course title, the number of Participants and task descriptions are presented below

\begin{tabular}{lll}
\hline Course & $\begin{array}{l}\text { Number of } \\
\text { Participants }\end{array}$ & Students were expected to \\
\hline $\begin{array}{l}\text { CC } 3724 \\
\text { Sociology of } \\
\text { Culture }\end{array}$ & 149 & $\begin{array}{l}\text { Write an online journal showcasing their understanding of a } \\
\text { specific topic in their course, and give feedback to their } \\
\text { classmates' journal. }\end{array}$ \\
$\begin{array}{l}\text { CC } 3759 \\
\begin{array}{l}\text { Digital Video } \\
\text { Production }\end{array}\end{array}$ & 19 & $\begin{array}{l}\text { Write a film review, and give online feedback to their } \\
\text { classmates' work. }\end{array}$
\end{tabular}

Teachers in both groups explained the project ethos to the students at the start of the semester. At the end of the semester, when all assignments were submitted and graded, evaluations of the Project were conducted in two parts. Firstly, telephone calls were made to all participants to invite them for a survey (Part I), in which they were invited to rate their level of agreement (1-Strong Disagree, 2- Disagree, 3-Netural, 4Agree and 5-Strongly Agree) on five statements. After that, 5 students from each group were randomly selected and contacted by telephone to share their views on their learning experience during the Project (Part II).

\section{RESULTS}

In this section, the results of the study are reported. The results of Part I are shown as follows:

TABLE 2: Survey Results for Part I*

\begin{tabular}{|l|c|c|c|c|}
\hline & \multicolumn{2}{|c|}{ Group A } & \multicolumn{2}{|c|}{ Group B } \\
\hline Statement & $\begin{array}{c}\text { The } \\
\text { Mea } \\
\text { n }\end{array}$ & $\begin{array}{c}\text { S } \\
\text { D }\end{array}$ & $\begin{array}{c}\text { The } \\
\text { Mean }\end{array}$ & SD \\
\hline $\begin{array}{l}\text { 1.The process of reading and giving } \\
\text { peer feedback helps me to understand } \\
\text { the course requirements. }\end{array}$ & 3.36 & 0. & 3.25 & 0.71 \\
\hline $\begin{array}{l}\text { 2.The process of reading and giving } \\
\text { feedback helps me to understand my } \\
\text { progress of learning. }\end{array}$ & 3.46 & 0. & 3.25 & 0.71 \\
\hline $\begin{array}{l}\text { 3.The process of reading and giving } \\
\text { feedback helps me to consolidate my } \\
\text { subject knowledge. }\end{array}$ & 3.48 & 0. & 4 & 1.07 \\
\hline $\begin{array}{l}\text { 4.I know how to improve my work by } \\
\text { reading feedback. }\end{array}$ & 3.23 & 1. & 3.25 & 0.71 \\
\hline 5.Overall, peer feedback helps learning. & 3.34 & 1. & 3.5 & 0.76 \\
\hline
\end{tabular}

*In Part 1, there were 94 respondents from Group A and 19 from Group B. The response rates were $64.8 \%$ and $42.1 \%$ respectively.

As shown, the mean value for each question is around 3, which represents "Neutral” among the ratings.

In Part II, all students (a total of 10 students from both groups) agreed that they were inspired by their classmates' showcase on the Platform. A student participant described his learning experience in the semester as followed: "You can take a look at others' work, get some useful ideas and have a more clearer picture of what are expected from the assignments." However, while students were generally positive towards the online peer feedback activities, all students said they would choose self-learning as their preferred learning-method. Details will be described in the following section.

\section{DISCUSSIONS AND RECOMMENDATIONS}

This section examines the possible reasons why online peer feedback did not receive strong support from students in this pilot study. Some recommendations for future research are also shared.

\section{[1] The time for revising work after feedback}

The key to the success of an online peer feedback activity is the strict control of the time for feedback. In the case of the study at hand, all Group A students commented that the time was too tight for them to revise their work after receiving peer feedback. "Only when I read and wrote comments in the Platform, I realised that there were lots of areas for improvement on my work. However, I had no chance to modify it because the work had already been submitted.”In other words, time needs to be allotted to permit students to give feedback to each other after their first draft is submitted online. This allows them to digest the feedback they received, connect their psyche to the new experience, amend their assignment before they submit their final product.

\section{[2] The Issue of efficiency}

A student in Group A said learning with feedback was not his cup of tea. He said he preferred to do more research on the Internet or read books, and he thought this method would be a lot more efficient than online discussions. He shared, "There would be no need for me to sit in front of a computer and read feedback which were, for the most part, not formative." Another student described self-learning and online discussion in this way: "Going to a destination by train (online discussion) is good because you can always see something through the window which is out of your expectation. Yet, a quick flight is much preferable, at least for me, as window siteseeing could seldom be very exciting."

From the metaphor of the quick flight and the slow train, author believes that teachers need to be aware of the time that students need to spend so that they could get familiar with the Platform. This is crucial to the success of the Project. For example, an attractive and user-friendly design of the Platform would be helpful [9][10], as both teachers and students do not need time to "digest" the technical functions of the new system.

\section{[3] Developing informal learning activities for ePortfolio}

At our College, many students are rushing at the last minute to complete the assignment on time with little thought of self-improvement. Given that they were cramming for their tight schedule in the so-called "peak season" for submitting assignments, they would not invest a lot of time to study peer 
feedback with the aim to refine one of the assignments without starting the second and the third one.

Comparatively, developing informal learning activity in the context of MAHARA might be another alternative to enhance students' learning. Informal learning, which refers to a learning undertaking [11], “on our own without externally imposed criteria or the presence of an institutionally authorised instructor”. If students could control their learning, and if learning was neither classroom-based nor highly structured, it would imply that students would be able to enjoy learning at their own pace in a more flexible manner.

\section{[4] Developing a sense of belonging to the Online Community in MAHARA}

From what the author learnt from the interviews, many students viewed the online peer feedback activity as a task to satisfy the course requirements, rather than as being part of an online community. As evidence for this assumption, Figure 1 below shows the percentage usage for the ePortfolio on the main server titled "HKCCSHARE".

The chart shows that the percentage of usage of the server CPU was particularly active in late March and mid-May 2012. These two peak times were the assignment submission periods for Groups A and B, respectively. Apparently, most of the participating students only logged onto the website when the assignment submission deadline was approaching.

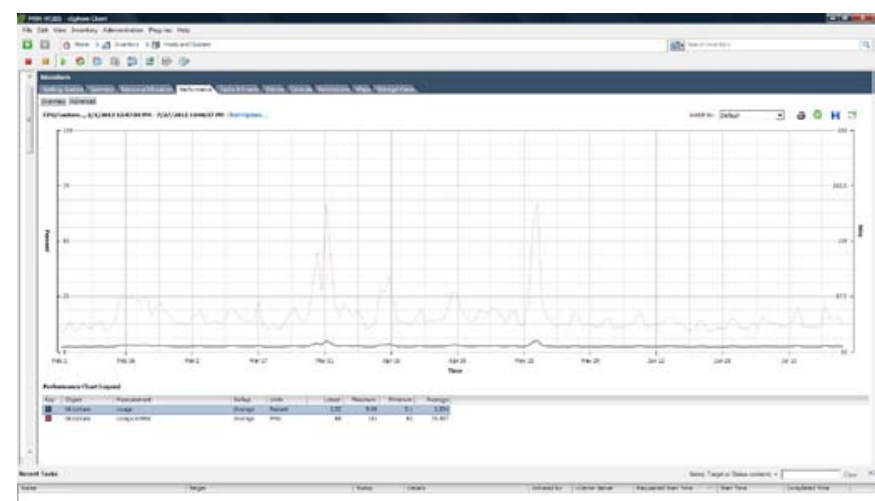

Fig.1: The percentage of CPU usage of the server in the academic year 2011-12

In short, the success of an ePortfolio project that supports learning from peer feedback largely depends on whether a social group is successfully constructed and whether the learners feel that they have a sense of belonging to that group.

[5] Developing instructions or directions for reflective learning assignments

An ePortfolio is an excellent reflective tool that demonstrates the user's growth over time [12]. Yet, before reflective Learning ePortfolios could be fully developed at the College, it might be important for teachers to develop a set of instructions describing what are expected in a reflective writing assignment. In our College, many courses currently require students to submit a reflective writing assignment. However, how this assignment should be done? Practice is differ from teachers to teachers. One teacher said that every week she would distribute a note memo to students and ask them to write down what learning outcomes they had achieved. Marks would be given at the end of the semester according to the memo, which would be collected back weekly from students. Another teacher shared that reflections were part of students' final report. Students should describe their learning process and no boundary would be given in this part. The author also heard that some students could freely share their feelings in their reflective writing and the teacher would judge their work case by case. If the requirements of reflective writing are so different in each course, can students develop their own reflective habits without depending on the teacher's intervention? This postulate is doubtful.

\section{LIMITATIONS}

There were some limitations in this study. The response rate of the survey and the number of interviewee are low. Yet, as shared earlier, the findings of this study could still serve as an active reference for readers who are interested in ePortfolio.

Moreover, although the findings are supported with survey and interviews, the present analysis is strongly based on the author's observation. In order to observe how things actually happen in this context, in the future, it might be good for the researcher to be involved in the classes, or we could include a formal sampling of the teachers' views on ePortfolios.

Nevertheless, as Wu [13] appropriately wrote, people could sometimes learn from "a casually dropped remark than from reading all the textbooks of philosophy." This article is written in this spirit by using data collected in an informal way so as to provoke further discussion. Moreover, it is evident that MAHARA is becoming more popular internationally in recent years. Yet, it is still a new topic with regards to enhancing students' learning in Hong Kong. The efforts spent on the Project could be important for future research.

\section{CONCLUSION}

To conclude, this article conveys the author's reflection on students' choices concerning their own learning strategies. The data collected from the pilot study, from the telephone survey and the interviews, are used to supplement her observation. The author's learning experience in self-learning and peer discussion was shared as an introduction to her analysis. The two major learning affordances of portfolios, which are to showcase students' knowledge or achievements, and to prompt students' engagement and reflections in learning, were described.

Two instruments were used in the pilot study: telephone survey and interviews. Although data showed that students generally were positive towards online peer feedback, some of them showed low interest in learning with peers when compared with self-learning. Future research of similar study could be more aware of the time given for students' feedback, so that they could have more time to polish their work after they have received the feedback from others. In addition, developing informal learning activities for ePortfolio could be 
an alternative to enhance learning. What's more, it might be important to minimize students' time to adapt to a new learning environment and an attractive and user-friendly ePotfolio system which require minimal or no training is preferred. Also, developing a sense of belonging to the online community seemed to be key factors of demotivation, as well.

Last but not least, it would be important for HEIs to think about developing clearer instructions for reflective learning assignments and perhaps develop common directions for all. At present, different teachers have different practices and this may adversely affect students in the development their reflective habits.

The major limitation of this study is the subjective nature of this article. Recommendations are based strongly on the author's observation. Though supplement data is provided, the low response rate of the telephone surveys and small sampling size of the telephone interviews may not provide a very comprehensive picture of the issue. However, despite these limitations, it is hoped that by sharing this experience, discussions over ePortfolios could be further provoked.

\section{ACKNOWLEDGEMENT}

This is to acknowledge the funding support from the Quality Enhancement Grant Scheme for the ePortfolio Project named "Implementation of an Open Source ePortfolio for Subdegree Students", and this article is a deliverable of the Project. Special thanks go out to Dr. Simon Leung, the Director of Hong Kong Community College, who has been offering his generous support in the implementation of this project.

\section{REFERENCES}

[1] L. Pang and P. Penfold, Chinese Learners' Perceptions of Blended Learning in a Hospitality and Tourism Management Program. Journal of Hospitality \& Tourism Education, 2008

[2] C.H. Leung and Y.Y.Chan., Mobile Learning: A New Paradigm in Electronic Learning. Proceeding of 3rd IEEE International Conference on Advanced Learning Technology, 2003

[3] T. Batson, The Electronic Portfolio Boom: What's it All About? Syllabus (now Campus Technology), vol. 16, no. 5; Retrieved from http://campustechnology.com/articles/2002/11/the-electronic-portfolioboom-whats-it-all-about.aspx (Accessed: September 6, 2012), 2002

[4] L.E. Wickersham, \& S. Chambers, ePortfolios: The first semester. Education, 127(1), 2006, pp.738-746

[5] E. Okoro, P. Cardon, and M. Washington. E-Portfolios in business communication courses as tools for employment. Business Communication Quarterly, 2011

[6] L.S. Vygotsky, Mind in society. Cambridge MA: Harvard University Press, 1978

[7] J. Feagin, A. Orum, \& G. Sjoberg. (Eds.). A case for case study. Chapel Hill, NC: University of North Carolina Press, 1991

[8] J. Gerring, What Is a Case Study and What Is It Good For? American Political Science Review 98 (May): 341-54, 2004

[9] A. Jafari, The "sticky" ePortfolio system: Tackling challenges and identifying attributes. Educause Review, July/August, 38-48. [verified 8 Feb 2007] http://www.educause.edu/ir/library/pdf/erm0442.pdf, 2004

[10] W. Meeus, F. Questier, \& T. Derks, Open source eportfolio: development and implementation of an institution wide electronic portfolio platform for students. Educational Media International, 43(2), 2006, pp.133-145
[11] D. Livingstone, Researching expanded notions of learning and work and underemployment. International Review of Education, 46, 6, 2000, pp. 493.

[12] H. Barrett, Portfolio Development Competencies, http://electronicportfolios.com/teachers/competencies.html, 2004

[13] S. Wu, Filling the pot or lighting the fire? Cultural variations in conceptions of pedagogy. Teaching in Higher Education 7(4),2002, pp. 387-395. 